\title{
EQUITY AND THE DISTRIBUTION OF ReHABILITATION PERSONNEL IN ONE Health District in the Western CAPE
}

\begin{abstract}
This paper describes a situation analysis of the rehabilitation personnel, employed by the state and non-governmental organisations, and the services available for people with disabilities in one health district in Cape Town. The recurrent cost of employing the rehabilitation personnel is analysed to determine how funding is allocated within the district. The results indicate that most expenditure on personnel is at two state institutions in the district,

\begin{tabular}{c}
\hline STRUTHERS P; \\
B.SC (Physiotherapy), \\
M.PHIL (Public Health)' \\
'Department of Physiotherapy, \\
University of the Western Cape. \\
\hline
\end{tabular}
with $76 \%$ of the expenditure at the regional psychiatric hospital and its residential facility for people with a profound intellectual disability. The balance - 24\% of expenditure - is the cost of employing rehabilitation personnel who provide a district level service. Seventy percent of this district level expenditure is at one special school that accepts $6 \%$ of children with disabilities in the district. A high percentage of intellectually disabled children and adults, with or without physical disabilities, do not have access to rehabilitation. There is minimal expenditure on employing rehabilitation personnel at the community heath centre. The only expenditure on community based rehabilitation is provided by the non-governmental organisation. The study demonstrates the inequitable distribution of funding for rehabilitation services within one relatively well-resourced health district and makes recommendations to facilitate change.
\end{abstract}

KEYWORDS: EQUITY; REHABILITATION; PERSONNEL COSTS; RESOURCE ALLOCATION; DISABILITY

\section{INTRODUCTION}

In any country the state has a responsibility to ensure equity in the provision of health services, including rehabilitation. As resources are always scarce, choices must be made and economic issues need to be explored (Normand, 1991). Major changes have taken place in the South African health system with the move to one integrated health system and the development of a district health system.

This study explores an aspect of equity in one health district in Cape Town. It describes a situation analysis of the rehabilitation personnel and the facilities available for people with disabilities. An analyses of the cost of employing the rehabilitation personnel is done to deter-

\section{CORRESPONDENCE TO:}

P Struthers

Department of Physiotherapy

University of the Western Cape

Private Bag X17

Bellville 7375

Tel: (02 l) 959-2542 (w) mine how funding is allocated within the district. It describes the methodology used to measure the cost of the services, and discusses the inequitable funding of rehabilitation services within this relatively well-resourced health district. This type of study can provide useful information to health service planners to assist with prioritising the budget allocation.

\section{BACKGROUND}

Since 1994 there has been a reorientation of the health system in South Africa to a primary health care approach, which has been implemented through the development of the district health system. The primary health care approach includes health promotion, prevention, curative care and rehabilitation (WHO 1978).

'Rehabilitation is the word used to describe ways of helping people with disabilities to become fully participating members of society, with access to all the benefits and opportunities of that society.' (White Paper on an Integrated National Disability Strategy, South Africa, 1997)
Rehabilitation can reduce the extent of permanent disability when therapy is provided early in the history of the disability. In South Africa, rehabilitation is provided in a number of contexts including hospitals, community health centres, schools, private practices and at home by physiotherapists, occupational therapists and speech and hearing therapists, assistants and community rehabilitation workers.

Analysis of the cost of rehabilitation can make an important contribution to planning health care services (WHO 1994). It gives an indication of the proportion of the total budget that is spent on rehabilitation services, where this spending takes place in the district, and who has access to the service. In addition, it enables planners to consider alternative uses of available funding. They may, for example, choose to use a greater or lesser proportion for a community based rehabilitation service.

The costs of any health service include both capital and recurrent costs. The capital costs include fixed costs such as the buildings. The recurrent costs 
are the costs of running the service. The main recurrent costs in the provision of a rehabilitation service are firstly the recurrent cost of the human resources the cost of employing the personnel - and secondly, assistive devices. This study only reports on the recurrent cost of the human resources.

\section{OBJECTIVES}

The objectives of this study were firstly to describe a situation analysis of rehabilitation services and facilities in the Mitchell's Plain Health District and secondly to determine the recurrent cost of the human resource component of the rehabilitation services.

\section{METHODOLOGY}

The methods of data collection and the calculation of costs are described.

\section{Research setting}

Mitchell's Plain was selected as the research setting, because the urban area forms a single distinct health district and the district level health facilities are mainly utilised by the local community. It was one of the earliest health districts to be established in Cape Town.

Mitchell's Plain lies $27 \mathrm{~km}$ from central Cape Town. It was developed in the 1970's as a dormitory town for 'coloured' people who were moved out of Cape Town under the Group Areas Act. It has a good infrastructure including tarred roads, electricity, safe water and telephones (Lalloo, 1994). At the time of the study, the population size was estimated to be 280710 (City of Cape Town, 1994/5). The confirmed prevalence of disability was $4.4 \%$ with $12.9 \%$ of the population having impairments (Katzenellenbogen et al, 1995). In actual numbers, this amounted to approximately 12351 people with disabilities of whom 3087 were children between the ages of 6-15 years.

The district has well established health and education facilities including the regional psychiatric hospital, a community health centre, a private hospital, a special school and a number of centres supported by non-governmental organisations (NGOs).

The situation analysis described all state departments and NGOs that pro-

Table 1: Rehabilitation personnel in Mitchell's Plain

\begin{tabular}{|l|c|c|c|}
\hline Facility for people with disabilities & Therapists & Assistants & Rehab workers \\
\hline $\begin{array}{l}\text { Lentegeur Hospital \& Care and } \\
\text { Rehabilitation Centre }\end{array}$ & 27 & 46 & \\
\hline Agape Cerebral Palsy School & 11 & & \\
\hline Lentegeur State Training Centre & 1 & & \\
\hline UWC Rehabilitation Project & 2.2 & & 4 \\
\hline Community Health Centre & 2 & & \\
\hline Private practitioners & 3 & & \\
\hline Beacon Training Centre & 0 & & \\
\hline Joy Day Care Centre & 0 & & \\
\hline Mitchell's Plain Special Care Centre & 0 & & \\
\hline
\end{tabular}

vide physiotherapy, occupational therapy and speech therapy. Secondly it described all the facilities available for people with a disability.

\section{Research design}

The study utilised quantitative methods to gather the data. The preliminary data were obtained from an independent survey that had been distributed by Disco-Chip, an umbrella organisation for organisations of, or working with people with disabilities in Mitchell's Plain. This questionnaire provided information on the numbers of people with disabilities involved in the organisation; whether they were children or adults; and the type of service offered by the organisation.

In this study on the costs of rehabilitation, further data were obtained, using a snowballing method, to identify other organisations in Mitchell's Plain that had links with people with disabilities. Phone calls were made to all the organisations, including all health facilities, special schools, workshops for people with disabilities, day care centres and disability related organisations. Key personnel, usually the person-in-charge or the head-of-department, were interviewed using a semi-structured interview to clarify and/or confirm questionnaire information on the numbers of people with disabilities. Information was also obtained on the numbers of therapists employed and who was funding their salaries. In total, 18 service providers were contacted and interviewed.

\section{Calculation of costs}

The recurrent cost of the rehabilitation personnel is the cost of their salaries. This was calculated using the 1996 state Personnel Administration Standard (PAS) salary scale, plus $40 \%$ for supplementary benefits. The low estimate of the cost was calculated using the lowest end of the scale and the high estimate of the cost was the highest end of the scale (WHO, 1994).

\section{RESULTS}

\section{Table I: Rehabilitation personnel in Mitchell's Plain}

Cost of rehabilitation personnel Regional and district level rehabilitation services

Seventy six percent $(76 \%)$ of the total expenditure on employing rehabilitation personnel was at the regional psychiatric hospital, Lentegeur Hospital, including the Care and Rehabilitation Centre for profoundly intellectually disabled people. This is the major psychiatric hospital for the Cape Metropolitan region, with most of its patients from outside the district. This cannot therefore be considered a district level facility, but is a regional facility. The remaining $24 \%$ of the total expenditure was dedicated towards rehabilitation services on district level for the entire population in the district.

\section{Graph 1: Expenditure on human resources providing rehabilitation (regional and district facilities)}


Graph 1: Expenditure on human resources providing rehabilitation

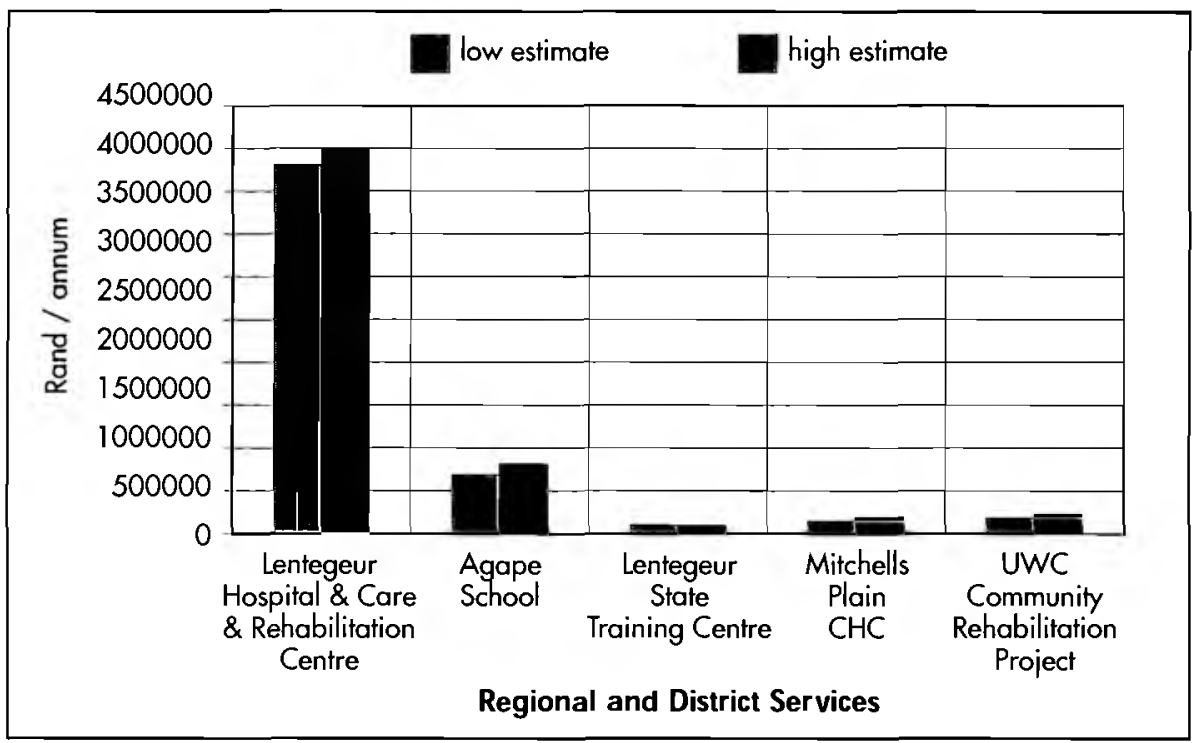

Cost of rehabilitation personnel District level rehabilitation services

Further analysis was done on the balance (the remaining $24 \%$ of total expenditure) that excluded the expenditure at the regional psychiatric hospital.

The greatest portion of expenditure

Chart 1:

Expenditure on rehabilitation

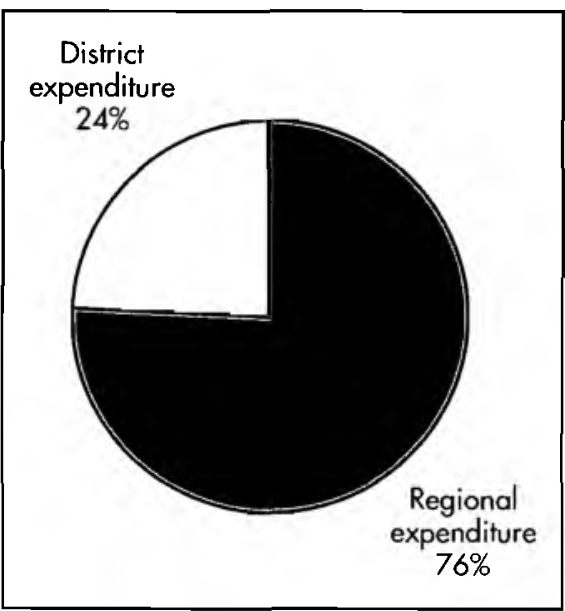

Chart 1: Expenditure on rehabilitation Chart 2: District level: Expenditure on disabled children

Seventy percent $(70 \%)$ of this district expenditure on rehabilitation was at the one special school for children with cerebral palsy, where 11 therapists were employed ( $79 \%$ of district based therapists) working with 190 children (6\% of the children with disabilities in the dis- constituted the employment of therapists working with children. A total of 506 children aged 6-15 attended special schools or day care centres in the district. This was only $16 \%$ of the total estimated population of children with disabilities aged 6-15 years in the district (see above total of 3087).

Chart 2:

Expenditure on disabled children

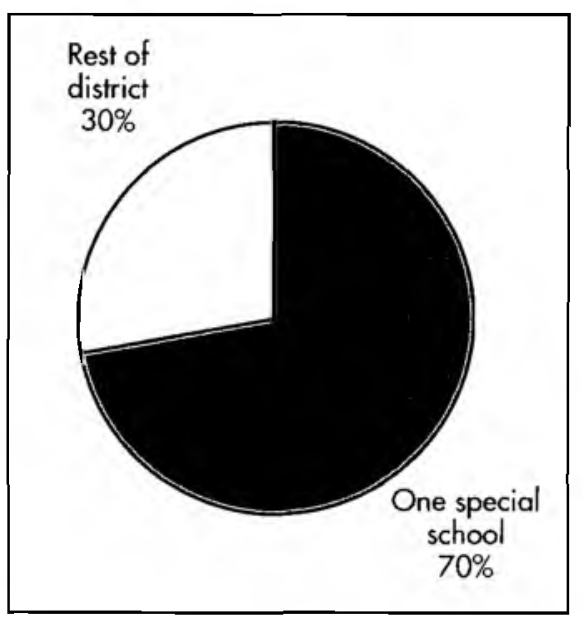

trict). As a part of the admission criteria, the school only accepted children with cerebral palsy with mild or no intellectual disability. The only funding for speech therapy service in the district was for children at this special school and this service was not available to the rest of the community. Most other centres providing a service to children with more severe intellectual disabilities did not employ therapists.
Table 2: Rehabilitation personnel for children at schools and care centres

At the district level, 17\% of the cost of the rehabilitation personnel was funded by the NGO, which provided community based rehabilitation for adults and children. Fifteen percent of the cost of rehabilitation personnel was at the community health centre, providing a service mainly for adults. At the time of the study all the state expenditure in the Mitchell's Plain Health District was on institutional based rehabilitation for adults and children.

\section{DISCUSSION}

The distribution of rehabilitation personnel in the Mitchell's Plain health district reflected a continuation of the history of state financial support to the employment of personnel at institutional level and not at primary level facilities within the community or community based rehabilitation. (None of the facilities referred to are tertiary institutions.)

The situation analysis indicated the concentration of rehabilitation personnel at two state institutions, Lentegeur Hospital and Agape Cerebral Palsy School. Only the clients of these institutions had access to therapists. People with disabilities at the other facilities, or those being cared for at home, could not get therapy from them.

An analysis of the cost of employing the rehabilitation personnel indicated that there were inequalities in the distribution of funding in the Mitchell's Plain health district. Apart from the regional psychiatric hospital, which accepted people from throughout the region, children who had an intellectual disability in addition to possibly having a physical disability had far less access to rehabilitation services than those with only a physical disability. At one centre for 160 children with intellectual disabilities there was only one therapist, and at three other centres that provided a day care service for 156 children with intellectual disabilities there was no state funding for rehabilitation personnel.

Funding for state therapists was from the provincial health department. The community based organisation had external donor funding. An evaluation is 
Table 2: Rehabilitation personnel for children at schools and care centres

\begin{tabular}{|l|c|c|}
\hline Centre & Children & Therapists \\
\hline Agape Cerebral Palsy School & 190 & 11 \\
\hline Lentegeur State Training Centre & 160 & 1 \\
\hline Beacon Training Centre & 104 & 0 \\
\hline Joy Day Care Centre & 20 & 0 \\
\hline Mitchell's Plain Special Care Centre & 32 & 0 \\
\hline
\end{tabular}

needed to determine what proportion of the province's budget goes on rehabilitation and whether it could be allocated more appropriately. Currently the therapists have no input in determining the budget allocation. There is a need for improved links between the Departments of Health, Education and Social Development to jointly determine where therapy posts are needed. The need for improved access to rehabilitation for adults and children has been demonstrated. This provision needs to be challenged by people with disabilities and their carers as well as by the rehabilitation personnel providing the service. Is it acceptable to provide intensive therapy to a few in institutions, while many have none?

The development of an inclusive education system also challenges the support provided by rehabilitation personnel working in the education sector. The Department of Education has emphasised the need for a paramount shift in the support currently provided to children in schools from "a narrow vision of a highly specialised, individually-focused service provision" (Department of Education, 1997: 23). The 2001 Education White Paper 6: Special Needs Education, Building an inclusive education and training system emphasises the need for removal of 'barriers to learning' within the education system (Department of Education, 2001). An accessible, integrated and health promotive approach is needed (Department of Education, 1997). This approach would facilitate the development of a more equitable way for rehabilitation personnel to provide a support service.

Equity is not the same as equality. It is about being fair and just. It is about the distribution of material resources as well as power. Realistic goals can help reduce inequities (Naidoo, 2000). While few will argue with the need for equity, it will only be possible at a price. With scarce resources choices will have to be made. What level of rehabilitation worker will we choose to employ? What benefits will be lost by making a different choice? Everyone wants a rehabilitation specialist on their doorstep but this can result in the specialist being under-utilised while the patients could be treated elsewhere at lower cost (Drummond et al, 1987).

In planning rehabilitation services, alternative uses of funding need to be explored. This may involve employing assistants or rehabilitation workers rather than therapists, if it is more cost effective but still with appropriate benefits. The Department of Education may for example consider employing this level of worker to provide support for children with special needs in mainstream schools.

Collaboration between the Departments of Health and Education is needed to plan effectively and appropriately. Within each health district a District Health Authority has being established which has the potential to play a significant role in planning and evaluating the health services at a local level. Intersectoral links are needed with the Education Management and Development Centres in the new education districts in the Western Cape to plan the provision of rehabilitation services.

\section{CONCLUSION}

The analysis of the cost of rehabilitation services is a useful indicator for determining whether funding is allocated equitably within a district. Mitchell's Plain is a relatively well off health district in terms of the number of rehabilitation personnel. However, a high percentage of children and adults with disabilities, particularly people with an intellectual disability, do not have access to the rehabilitation services in the district. Excluding the regional psychiatric hospital, most funding is at one special school, which has the only funding for speech therapy in the district. Most of the resources go towards the therapists providing the service for children with a physical disability without an associated intellectual disability. A very small percentage of the Community Health Centre budget goes towards employing rehabilitation personnel.

Without access to rehabilitation, people with disabilities may be unable to reach their full potential, denying them the chance of integration into society. Inadequate or inappropriate funding of rehabilitation services will continue to lead to the marginalisation and impoverishment of people with disabilities.

Health service planners, planning rehabilitation services, need to familiarise themselves and analyse the cost of all the rehabilitation services provided by state and NGOs at the district level to ensure equity within a district. This analysis could then be used to compare different districts to enable the provincial level planners to set priorities for planning services and secondly to enable people with disabilities to have access to appropriate and affordable rehabilitation.

\section{RECOMMENDATIONS FROM THE STUDY}

- That each district health authority develops a directory of facilities, rehabilitation personnel and numbers of clients with disabilities to facilitate planning.

- That there is joint planning between the Departments of Health, Education and Welfare to plan for the provision of education support services for children.

- That there is increased funding for employing rehabilitation personnel to work with children who have a moderate or severe intellectual disability.

- That there is a greater proportion of funding for adults with disabilities in the district.

- That there are further studies in other districts of the Cape Metropole to compare districts and inform planners in the Provincial Administration of the Western Cape. 


\section{REFERENCES}

City of Cape Town 1994/5 Annual Report of the Medical Officer of Health

Department of Education 1997 National Commission on Special Education Needs in Education and Training/National Commission on Education Support Services (NCSNET/ NCESS). Quality Education for AIl: Overcoming barriers to learning and development. Department of Education, Pretoria

Department of Education 2001 Education White Paper 6 - Special needs education: Building an inclusive education and training system. Department of Education, Pretoria

Drummond M, Stoddart G, Labelle R, Cushman R 1987 Health Economics: An Introduction for Clinicians. Annals of Internal Medicine 107: 88-92

Katzenellenbogen J, Joubert G, Rendall K, Coetzee T 1995 Methodological issues in a disablement prevalence study: Mitchell's Plain, South Africa. Disablement and Rehabilitation 17(7): 350-357
Lalloo R 1994 Equity and the Allocation of Health Care Resources at District Level. Unpublished Thesis, University of the Western Cape, Cape Town

Naidoo J, Wills J 2000 Health Promotion: Foundations for Practice, 2nd ed. Balliere Tindall, London: 194-195

Normand C. 1991 Health and the economics of health. British Medical Journal 303: 1572-1577

Office of the Deputy President T M Mbeki 1997 White Paper on an Integrated National Disability Strategy, Pretoria

World Health Organisation 1978 Report on Primary Health Care, Alma Ata. September, Geneva: 6-12

World Health Organisation 1994. Cost analysis in Primary Health Care - A training manual for programme managers. Creese A, Parker D (editors). Geneva: 33-35

\section{ACKNOWLEDGEMENT}

Advice from Prof. D McIntyre, Health Economics Unit, University of Cape Town 